\title{
Tríade Design-Interdisciplinaridade-Complexidade: o poder da relação do jovem de baixa renda com a universidade
}

Triad Design-Interdisciplinarity-Complexity: the power of the relationship of the lowincome youth with the university

Moreira, Marina; Doutora; PUC-Rio

marinamoreira@hotmail.com

PINA, Fernanda; Doutoranda; PUC-Rio

pina.fernanda@gmail.com

RIPPER, José Luiz; Livre-Docente; PUC-Rio

neampucr@puc-rio.br

\section{Resumo}

Este artigo continua investigação que analisa as experiências vivenciadas por jovens de comunidades de baixa renda no ambiente universitário. Retoma-se questões relativas à interdisciplinaridade, o papel social da universidade e o contexto destes jovens norteadas pelo do Design. Este Design, entendido um processo para tratar questões complexas, referente a inclusão destes jovens na universidade, reforçando a tríade Design-Interdisciplinaridade-Complexidade. Complementar a uma primeira coleta de dados realizada junto a jovens envolvidos com atividades promovidas por um núcleo interdisciplinar e um laboratório de Design da PUC-Rio, publicada no P\&D 2016, este artigo retrata outra fase, apoiando a identificação de características do desenvolvimento humano. As atividades estão pautadas em um objetivo de transformar diferentes escalas: vegetal, animal e biológica. Tais transfomações se motraram fontes de ações e escolhas, uma aventura provinda da curiosidade e fazeres, que reforçou a capacidade desses aprendizes a contruir, compartilhar e avalliar novas informações, os levando a novas perspectivas.

Palavras Chave: Design; jovem de baixa renda; universidade.

\begin{abstract}
This article continues research that analyzes the experiences of young people from low income communities in the university environment. Resume issues related to interdisciplinarity, the social role of the university and the context of these young people guided by the Design. This Design, understood as a process to deal with complex issues, concerning the inclusion of these young people in university, reinforcing the Triad Design-Interdisciplinarity-Complexity. Complementing a first data collection conducted with young people involved in activities promoted by an interdisciplinary nucleus and a PUC-Rio Design Laboratory, published in the P \& D 2016, this article portrays another phase, supporting the identification of human development characteristics. The activities are based on a goal of transforming different scales: vegetal, animal and biological. These transformations were fueled by sources of actions and choices, an adventure derived from curiosity and doings, which reinforced the ability of these apprentices to build, share and gather new information, leading them to new perspectives.
\end{abstract}

Keywords: Design; low-income youth; university. 


\section{Introdução}

Vivenciamos trajetórias onde estamos inseridos em um mundo competitivo, que nos exige um lugar de destaque numa sociedade capitalista. Neste difícil contexto da diversidade social, tornase quase impossível que jovens oriundos de famílias de baixa renda possam se encontrar num futuro próspero, trazendo o conhecimento como ganho certo e lutando pela sobrevivência do cotidiano. A vivência da autora em um núcleo que há mais de 30 anos se propõe a facilitar a vida desses jovens, por meio da atuação social da universidade, levou a constatação de que a guerra é pesada. A formação recebida na infância e na adolescência ajudou até aqui nesse enfrentamento.

Em artigo públicado na edição anterior deste congresso, foi apresentado o Núcleo de Estudo e Ação sobre o Menor (NEAM) da PUC-Rio e seus desafios de inspirar, acolher e facilitar a realização de jovens que buscam um futuro no exercício de viver o conhecimento. Sua bases se deram na vontade de passar o conhecimento através de um desenho vivo, dedicando-se a exaltar aos pesquisadores da universidade, a possibilidade de se ver um mundo exterior: a observar fenômenos sociais para o avanço da ciência e da iniciativa interdisciplinar com vistas a construir um novo ambiente. Quando se pensou o NEAM, reuniu-se durante vários meses, diferentes professores de quase todos departamentos da PUC-Rio para discutir a interdisciplinaridade de um núcleo estudando a criança e o adolescente, em circunstâncias difíceis.

A promoção da vida, em todas as suas manifestações, é lema do NEAM, agindo diretamente nas relações humanas fixadas em um convívio acadêmico. Com criatividade, alternativas transformadoras do bem-estar e justiça social se dão como uma consequência natural. Ao projetar suas ações, o NEAM imagina condutas férteis e ricas, motivado sempre pelo desejo de ver o crescimento do ser humano, prefazendo aquilo que julga ser moralmente correto.

Tudo o que é moralmente correto deriva de quatro fontes, como apontava o filósofo romano Cícero (45-4 a. C.): (1) a plena percepção ou desenvolvimento inteligente do que é verdade; (2) a presença de uma sociedade organizada em que todo homem recebe e merece e cumpre suas obrigações; (3) a grandeza e a força de um espírito nobre e universal; (4) a ordem e a moderação no que é dito e feito. Tal afirmação, ainda hoje usada em argumentações jurídicas, exige ações rápidas e eficazes, uma vez que nosso mito de criação cultural está mais ligado em evidências sólidas e científicas do que na arte da profecia e da intuição.

O NEAM sofre com a falta de compreensão, diante da irresponsabilidade de alguns, mas, tem alegrias e ansiedades certas, tendo aprendido a conviver com a adversidade e os obstáculos, seja do meio universitário ou externo. Tem a capacidade de antever que estaremos todos trabalhando juntos para o bem comum coletivo mergulhando em situações cada vez mais complexas. De mãos dadas, em atitude colaborativa em sintonia com a missão da universidade, que segundo Pe. Laércio Dias, reitor em exercício quando o núcleo foi criado, deveria considerar que:

Todo ser humano, qualquer que seja sua idade, sexo, raça, cor, língua, condição de saúde, confissão religiosa, posição social, econômica, ideológica, política, cultural, é portador de uma dignidade inviolável e sujeito de direitos e deveres que o dignificam em sua relação com Deus, como filho; com os outros homens, como irmão, e com a natureza, como senhor. Por isso, todos os seres humanos são fundamentalmente iguais em direito e dignidade, livres para pensar e decidir de acordo com a sua consciência; para expressar-se, organizarse em associações e buscar sua plena realização, mas em profundo respeito à liberdade e dignidade dos outros seres humanos, tendo sempre em vista o bem comum (DIAS de MOURA, 1996) 
Contar a história das lutas para convencer pessoas e instituições a apostar em novas iniciativas, poderia ser um caminho natural para este artigo. Formas de buscar o verdadeiro progresso, fruto da coragem de arriscar e não da acomodação da permanência, complementaria esta opção. No entanto, mais que histórias, além das formas, buscou-se elencar pontos norteadores para geração de atividades universitária voltadas para o empoderamento de jovens de comunidades de baixa renda, especialmente na conquista de uma vida acadêmica promissora.

Neste percurso metológico e no anterior a proposta de pesquisa está no relato de pequenas vitórias significativas que tornam o NEAM um "Laboratório da Esperança", tal qual cunhado por outro reitor da PUC-Rio, Padre Jesús Hortal Sánchez, S.J., em sua obra "A Universidade: realidade e esperança", publicada em 2002. Assim, para atender a meta de criar oportunidades para a socialização e integração dos jovens no ambiente universitário, preservando a valorização dos benefícios socioambientais, estabeleceu-se uma parceria com o Laboratório de Investigação em Livre Desenho (LILD), vinculado ao Departamento de Artes \& Design da PUC-Rio, coordenado pelo Professor José Luiz Mendes Ripper, com a intenção de promover ações e medir seus resultados.

Essa opção deveu-se, essencialmente, ao fato de o Design ser um campo de vocação interdisciplinar e de natureza tecnológica (COUTO, 2014) que tem no Design Social uma de suas abordagens metodológicas; que orienta as práticas do LILD, um laboratório dedicado às questões ambientais e ao desenvolvimento de tecnologias em coautoria com as comunidades. Como ponto de partida notamos a necessidade de novos questionamentos, de uma mudança de atitude na abordagem do objeto de pesquisa, de forma a observar o conjunto como um todo. Daí a relevância da interdisciplinaridade e não de uma fragmentação dos saberes. De acordo com Couto (1997):

\begin{abstract}
A interdisciplinaridade pressupõe novos questionamentos, novas buscas, transformação da própria realidade. Implica uma mudança de atitude, que possibilita o conhecimento, por parte do indivíduo, dos limites de seu saber para poder acolher contribuições de outras disciplinas. Interdisciplinaridade deve ser, pois, entendida antes de tudo, como atitude, pautada pelo rompimento com a postura positivista de fragmentação, visando à compreensão mais ampla da realidade. Através dessa postura é que ocorre a interação efetiva, sinônimo do interdisciplinar. (COUTO, 1997)
\end{abstract}

Essa opção justifica-se ainda pela aproximação do NEAM com a potencialidade do Design. É, nesse momento, que se faz necessário provocar uma nova ordem exigida através de projetos emergentes dedicado a situações complexas que, por sua vez, desencadeiam novas relações entre causas e efeitos. Diante deste contexo criou-se a hipótese de que os processos de educação e integração social dariam ao jovem a oportunidade de obter uma educação abrangente em que identificassem causas, e indicassem caminhos de socialização e mantivessem neles o valor de pertencimento. De maneira complementar acreditava-se que ao relatar uma experiência interdisciplinar bem-sucedida de valorização do pertencimento e de desenvolvimento técnicoprofissional, esse mesmo jovem poderia vislumbrar novas opotunidades de vida e contagiar tantos outros do seu meio. O que prefaz um substancial impacto social por meio do Design.

\title{
2 Pontos norteadores para geração de atividades universitária para jovens de comunidades de baixa renda
}

Como objetivo principal deste estudo, propomos então analisar e refletir o valor de ações interdisciplinares como pilar para um olhar sobre o jovem como agente transformador do seu ambiente, amparado por experiências desenvolvidas no ambiente universitário. Assim, os objetivos específicos do presente artigo se resumem em: (1) registrar os resultados da ações 
interdisciplinares, desenvolvidas junto a jovens de comunidades de baixa-renda, onde o Design contribuiu, em uma teia de relações sociais, singularizando, o espaço da ação, dando ênfase ao resultado do desenho coletivo; (2) criar um conjunto de diretrizes, para práticas que revigore o uso, seleção e reutilização de variados materiais e objetos descartáveis, como fonte para a aquisição de melhores condições da vida em comunidade.

Em síntese, a intenção por meio de um processo metodológico foi a de analisar intervenções sociais realizadas pela parceria NEAM-LILD-Comunidade com foco no desenvolvimento de soluções. Como recorte de pesquisa, optou-se por uma investigação à luz de uma ação, desenvolvida no período de 2015.1 a 2017.2 envolvendo agentes multiplicadores do Design, do NEAM e de membros de comunidades de baixa-renda. A referida ação, como já mencionado foi dividida em dois momentos, uma registrada em Moreira et. al (2016) e outra aqui registrada. Em ambos momentos, a convivência dos jovens foi regida por materiais naturais como o bambu, barro e folhas vegetais, incluindo a taipa. O foco da pesquisa foi, portanto, verificar o impacto dessa ação na formação e expectativas dos jovens do NEAM, reforçando uma história de parceria entre o núcleo e o Design Social. Para tanto alguns pontos precisam ser elucidados.

\subsection{A Universidade como promotora de experiências transformadoras, por meio da interdisciplinaridade}

Ampliar a ação extramuros da PUC-Rio, participando da melhoria das condições de vida da comunidade do entorno, fez a interdisciplinaridade ocupar, sem dúvida, um lugar de destaque. Passados 36 anos, é possível afirmar que a PUC-Rio tem hoje condições de destacar demandas manifestas de resultados pelos anos de colaboração universidade-comunidade. O NEAM comprova que, por meio de suas ações e projetos, está sempre na vanguarda, optando por um trabalho concreto, visando o desenvolvimento das capacidades de crianças e adolescentes. Ainda assim convive-se com contradições existentes, o pluralismo cultural e a complexidade da vida moderna. No entanto, preserva a alegria, bondade, paz e amor pelo outro.

Assim, a cultura, em seu significado maior, pressupõe a cosmovisão de um povo e da pessoa humana que vive um determinado contexto, tendo a ver com o modo de existir no mundo e de buscar sua identidade. É a força de criação e de inovação, estabelecendo uma ponte entre transmissão e transformação. Uma educação criadora implica num conjunto de iniciativas e ações que levam à abertura das ideias, à procura de soluções inovadoras, facilitando condições para que sejam transferidos os conhecimentos a situações da realidade social e cultural, especialmente as relacionadas so cotidiano de jovens de baixa renda, que a principio não estima (ou não vê possibilidades) de seguir uma vida acadêmica para além do ensino médio.

Considerando que a universidade dispõe de informação de grande relevância para a sociedade, estimular a troca entre saber científico e o saber popular seria propiciar maior legitimidade institucional, estimulando a prática de um pensar criativo. Reformular a política da palavra academia é, contudo, um desafio, uma vez que a informação trata novas possibilidades de interação com as práticas sociais ao buscar novos significados, mesmo porque, a lógica da contradição e o espaço da incerteza pontuam o cotidiano das vivências coletivas e promove novos conheceimentos.

É intenção da Universidade que esse conhecimento seja abordado numa visão interdisciplinar, a fim de que possa ser inovador e provocar as desejadas mudanças sociais. A integração entre Universidade e a comunidade permite evidenciar as contradições, mas com o 
propósito de desmistificar essa política de "palavra da academia". Na Universidade do futuro será primordial partir para uma compreensão mais aprofundada das mutações processuais (libertando cientistas, professores, artistas e profissionais do aprisionamento intelectual), redimensionadas em cenários mais abrangentes. Isso levaria o homem à construção de novos conhecimentos, inseridos na sua realidade históricocultural, possibilitando uma efetiva melhoria da qualidade de vida e o tão almejado bem-estar social.

O fato concreto é que pessoas diversas, inseridas ou excluídas, convivem em uma fase de modelos socioculturais de diversas naturezas. Ações interdisciplinares procuram, assim, resgatar o sentido humano para a vida, possibilitando o diálogo com o mundo. Através das redes de conexões para propiciar, sem dúvida, um mergulho nas situações, reavendo a dinâmica do movimento advindo da produção de diferenças. Produzir instantes de construção e desconstrução, nesta contraditória pós-modernidade, é mais uma de nossas intenções.

\subsection{O contexto do jovem de comunidades de baixa renda e seu registro de memória}

Na sequência dos conceitos desenvolvidos por Bergson (1896), em "Matière et Mémoire "A memória exprime a ligação do nosso espírito ao nosso corpo e do nosso corpo com o mundo social e natural que nos rodeia" (FENTRESS; WICKHAM, 1992, p. 57). Assim, a "Memória Individual" converte-se em "Memória Social" através da partilha de lembranças com os outros, num contexto específico, de um determinado grupo social, quer este grupo seja estruturado e duradouro, quer seja informal e temporário. Nesse sentido, Bergson enfatiza que "com efeito, a experiência passada recordada e as imagens partilhadas do passado histórico são tipos de recordações que têm particular importância para a constituição de grupos sociais no presente" (2010, p. 41). Logo este tipo de partilhas, de memórias, fortalece a relação dos grupos.

Halbwachs (2006), na sua obra mais emblemática, "La Mémoire Collective", aborda a Memória Coletiva e a Memória Individual, concluindo que antes da Memória Coletiva existe uma Memória Individual. É, então, devido à pertinência do tema em causa no grupo social em que o jovem de comunidades de baixa renda está inserido, decorrendo na formação da sua Memória Coletiva. $\mathrm{O}$ autor enfatiza que a Memória Coletiva é unicamente recordada através dos elementos de um grupo.

Portanto, o que recordamos, enquanto indivíduos, é sempre condicionado pelo fato de pertencermos a um grupo. Os momentos que só a nós próprios nos incluem se devem ao fato da recordação se situar na "fronteira" de todas as "interferências coletivas" que correspondem à vida dos grupos, situando-se na interseção de diversas correntes do "pensamento coletivo" (HALBWACHS, 2006, p.12).

Na perspectiva do autor, não nos lembramos de nossa primeira infância porque nossas impressões não se ligam a nenhuma base enquanto ainda não nos tornamos um ser social. Tal afirmação nos leva ao fato de que é justamente do grupo familiar que tais impressões se transformam em lembranças sociais. Isso, considerando que a construção do sentido do tempo para a História, essência do saber histórico, relação que envolve pensar o passado e sua relação com o presente.

Para Pollak (1992), a memória também passa por uma herança, que se concretiza ao juntarmos todos os acontecimentos vividos, que podemos assumir como a existência de uma regionalidade de acontecimentos que nos marcam tanto a um grupo quanto a uma região, 
transformando a memória herdada. Para o autor, as lembranças e memórias, muitas vezes herdadas por uma transferência, são coisas mutáveis. Elas sempre se reconfiguram, a partir das experiências ao longo de nossas vivências.

Exemplificando, professores observam uma multiplicidade de dados e elementos que se interagem e acabam constituindo a memória individual, coletiva e histórica de alunos que, em geral, são considerados apenas como sujeitos que se definem por sua situação presente. É comum não ocorrer a observação de que a constituição da relação do pensamento passado/presente nos alunos está entremeada por situações vividas, ou transmitidas, por aqueles que os circundam. Nessas situações, memórias transmitidas, estão implícitas questões sociais, econômicas e culturais, transformações tecnológicas e costumes. A memória que os alunos têm participa da constituição de seu presente, evidenciando a memória das dificuldades vividas por pais e avós.

Em linhas gerais, esse passado também é referenciado de diversas maneiras, revelando o que seriam, segundo Halbwachs (2006), os vários pontos de vista sobre a memória coletiva. Em paralelo ás referências de acessibilidade e possibilidade de consumo, é possível detectar, também, frases como "era mais sossegado", "não era perigoso" ou "não havia violência", uma vez que, por exemplo, citadas por alunos, conotam o aumento da violência em algum setor. Ao mesmo tempo, há afirmações como "as crianças brincavam mais" ou "mais engraçado" que revelam certa nostalgia, uma visão positiva sobre esse passado.

Quando se fala em comunidade, fala-se de histórias de vida e, em muitas vezes, nos depararmos com a preocupação acerca da memória herdada, da fama a ela enraizada. As comunidades se mantêm em torno do "glamour" a ela associado, mesmo que para este glamour esteja associado a ser reduto da marginalização ou espaço pitoresco guardador do segredo daquilo que não se conhece. A Rocinha, por exemplo, contexto do qual advém a maioria dos jovens envolvidos com o NEAM, tem sido vista como "fábrica de marginais". Apesar de toda essa imagem negativa, nos últimos anos, o glamour dessa favela, que é uma das maiores da América latina, vem sendo revelado diante dos recentes movimentos de pacificação empreendidos.

As barreiras entre ela e o "asfalto" vem sendo derrubadas, mas ainda existe o preconceito por parte da sociedade que não entende que a favela precisa ser enxergada como parte integrada da cidade. Esse preconceito é originado pela falta de conhecimento e é alimentado pelo medo do velho mito de que todo favelado é marginal. Desconsidera-se assim que é no improviso que os valores culturais são desenvolvidos e é dele que surge a vivencia cultural, a memória coletiva de quem nela convive, ou quem a ela observa.

A Rocinha revela-se rica e fértil no que diz respeito à criação cultural. Nas ruas, becos, e vielas, tudo tem virado palco para a arte. Nem mesmo a falta de infraestrutura impede que as manifestações culturais persistam, fortalecidas pelo ideal de tornar as pessoas mais felizes e capazes, oferecendo uma vida interessante e com grande responsabilidade sociocultural. Nesta perspectiva, pode-se tornar um imenso prazer transitar na Rocinha e se deparar com os pequenos grupos de artes plásticas, dança, teatro, poesia, música, entre outros, que através da arte estão contribuindo para a formação de centenas de moradores. De acordo com Gilberto Velho (2003, p.19), a participação sociocultural do homem é requisita para sua existência: “O homem só existe através da vida sociocultural e isolá-lo desta, mesmo em termos puramente analíticos, pode deformar qualquer processo de conhecimento".

É preciso, portanto, mudar o indivíduo de dentro para fora. Já está comprovada a 
importância da cultura nessa transformação. Aliada à educação, será possível ver, de fato, uma transformação verdadeira e eficaz para um povo que viveu, por muitos anos, abandonado pelo governo e que busca, com toda coragem, uma nova vida, digna e respeitosa. A cultura é resultado da memória individual, coletiva e herdada. Isso significa que os conceitos de memória apresentados, cirandam a formação cultural e identitária da comunidade. É assim que se obtém e promove substância ao jovem oriundo da comunidade até seu contato com o meio acadêmico. Valida-se assim, a ideia de que o foco na violência pode ser desmistificado através desta multiplicidade de diferentes fazeres, promovidos por estas iniciativas de caráter cultural, que anulam uma possível visão individual depreciativa, transformando-a em autoestima.

\subsection{A orientação do Design: registro de um campo e feedback dos usuários em questão}

No social, a cultura tem o papel fundamental que é de qualificar o potencial humano; melhorar a autoestima; incentivar as trocas sociais e culturais; estimular a cidadania, além de corroborar com os laços de identidade e cooperação e amenizar os estereótipos e preconceitos sofridos pelos moradores - O Design interfere, assim, na cultura e na comunidade.

Muitas vezes, percebemos que o jovem na comunidade foram se tornando agentes de uma ação multiplicadora de um novo comportamento, frente à questão cultural, ao mesmo tempo em que interferiram na vida da comunidade (MOREIRA et. al, 2016). Entendemos então que ter clareza acerca das memórias individuais, coletivas e herdadas é vital para o designer como profissional-cidadão, ter sustentação para levar em conta a legitimação dos contextos de que participa, oferecendo visibilidade e validando a importância da cultura na transformação do ser humano. Daí o designer estar intrinsicamente ligado ao desenvolvimento sociocultural de cada indivíduo.

Esta postura nos permite, através de uma ação interdisciplinar, realizar uma tentativa de fuga da esgotada neutralidade científica em direção a um enlace mais radical com o trabalho de educação. Entendemos, com isso, que as várias áreas produzem diferentes escutas. E é justamente na dimensão da diferença que se encontra síntese provisória, uma vez que proporciona fôlego para mais debates que são revertidos na ação da pedagógica. Configura-se nesse trabalho, portanto, um grupo sociocultural que não o da Universidade, e um outro grupo de trabalho (com relação às diferentes disciplinas do próprio Projeto), o que possibilita um enriquecimento do conhecimento em toda sua amplitude.

A educação, no sentido de aquisição de conhecimento e experiência, é proposta como uma via de mão-dupla. Evidentemente, um enfoque psicológico do processo educativo e da interação social em pauta neste Projeto, bem como a interpretação das percepções do meio ambiente, em especial do lixo, nesse grupo de adolescentes, provindos de comunidades de baixa renda, viabilizaram as representações simbólicas, subjetivas e de significados sociais. Assim, o exercício da interdisciplinaridade foi fundamental para o andamento do Projeto.

\section{Relações dos métodos de pesquisa com as intervenções apoiadas pelo Design}

O Design tem a perspectiva de trabalho conjunto de modo que uma abordagem seja bem caracterizada pelo conjunto de ações em grupo. Essa a aideia implantada dentro do LILD, com a supervisão do Prof. Ripper. Para os jovens do NEAM, essas ações dentro da proposta do LILD, foi percebida como uma coletânea de práticas, estratégias e de buscas de propósitos finais para os usuários que tornam parte do compromisso (projeto) a ser despertado. Nesse contexto, se alterou toda a concepção do trabalho já conhecida pelos jovens participantes, mas lhes deu uma visão efetiva e totalmente diferente de tudo que já tinham visto, ou vivenciado como aprendizes.

As ideias, em torno dos projetos propostos sempre fluíram, de maneira que os envolvidos 
tinham ciência do que acontecia para alcançar objetivos determinados. Desta forma, as atividades tomaram seu curso normal, cheio de novas perspectivas, devido à diversidade de objetos. Os alunos entenderam que esse processo de construção de figuras envolvia matemática, geometria, por exemplo. Todas as ações aconteceram de acordo com as propostas, que se resumia na integração sócio-acadêmica, embora, houvesse uma grande cobrança em torno de resultados sobre o desenvolvimento técnico e apropriação do saber de maneira criativa, com o foco no uso de técnicas diversas para o alcance do objetivo principal, que era a transformação do produto em pesquisa.

Como percurso metodológico, estabelecemos uma abordagem pertinente à natureza do contexto da questão norteadora e dos alunos envolvidos. Para a verificação do impacto da ação nos comportamentos e nas atitudes demonstradas pelos alunos, elencamos os seguintes indicadores que emergiram da própria realização dos alunos e que foram: (1) respeito às individualidades e peculiaridades dos membros da comunidade; (2) atitudes abertas para novas experiências; (3) diálogo consistente e direto entre os participantes; (4) permanente troca de ideias e opiniões; (5) delineamento conjunto das metas prioritárias e (6) Discussão de alternativas de trabalho e pontos positivos e negativos do trabalho realizado.

Concretamente foram considerados os documentos de resgate da história de vida do NEAM, a observação das manifestações espontâneas, declarações, entrevistas presenciais em um primeiro momento (MOREIRA et. al, 2016) e o registro de novas manifestações, por meio de questionário online e revisão do perfil dos jovens envolvidas, bem como o desempenho dos alunos e dos professorores "facilitadores" em casa intervenção/atividade neste segundo momento, neste artigo relatado.

\subsection{A relevância da Pesquisa Ação para fundamentação do Design Participativo}

O design, nesta proposta, tem o papel fundamental de instrumentalizar os envolvidos na troca de saberes. É o ponto de mediação, no qual as partes têm possibilidade de expressar sua compreensão de mundo. Destaca-se a importância de alguns parâmetros para a análise desta soma de conhecimentos: $O$ envolvimento comprometido dos grupos no que é posto como premissa; $\mathrm{A}$ garantia da pessoalidade a cada um dos jovens, em atuação no Laboratório de investigação em Livre Desenho (LILD); Planejamento flexível, com apoio à isonomia nas atividades apresentadas e à autonomia no realizar, principalmente; a Interação sem julgamento de qualquer natureza; a eficácia na produção de descobertas; e a meta definida para a aplicação dos resultados obtidos.

Todas essas considerações sobre metodologia vieram ampliar a atuação do NEAM e do LILD, em sintonia com a dinâmica de atuação do Design Participativo, por meio do método de pesquisaação. A pesquisa-ação é um tipo de pesquisa social que é concebida e realizada em estreita associação com uma ação ou com a resolução de um problema coletivo e no qual os pesquisadores e os participantes representativos da situação da realidade a ser investigada estão envolvidos de modo cooperativo e participativo (THIOLLENT, 1985, p.14).

Tal processo de pesquisa pode ser relacionado com a abordagem metodológica do Design Participativo, já que ambas são centradas no outro, como parceiro de pesquisa e ao mesmo tempo potencial usuário do que se desenvolve por meio da cocriação. A característica dessa abordagem, segundo Bianco e Damazio (BIANCO; DAMAZIO, 2007) é fazer com que os profissionais apliquem o design pensando no contexto social e focando no indivíduo. O comprometimento e contato direto do designer com o usuário e o contexto que o projeto se apresenta são os pontos marcantes da prática do Design Participativo. 
Ter o jovem como ser falante, foi ter um parceiro na produção de um conhecimento compartilhado. Pesquisar "com", segundo Carvalho (2015), não significa que o lugar do pesquisador desapareça, nem que ele se tornará igual ao objeto da pesquisa, pelo contrário, é uma postura metodológica que permite que aconteça a troca dos saberes na busca da produção de um conhecimento. Portanto, esta pesquisa se caracteriza pela geração de um conhecimento que busca a integração do saber local de uma comunidade, junto a área do design, resultando na construção de um novo conjunto de saberes para ambos.

Portanto, é possivel dizer que foi realizada uma pesquisa-ação nos dois momentos de pesquisa, visando atuação transformadora, por meio da troca e da associação de conhecimentos, com a prática e o cotidiano da comunidade. Esse processo corre de forma dinâmica entre os saberes popular e acadêmico, tendo por objetivo a criação de métodos e técnicas capazes de gerar formas de tratamentos da realidade. Esses métodos objetivaram levar o jovem a falar abertamente sobre suas vivências e perspectivas, por meio de técnicas diferentes, mas sem perder seu papel de coautor das ações aplicadas a eles mesmo.

\subsection{A nova técnica de entrevista e sua importância na coleta de novos dados}

Destaca-se que o conteúdo (para organização do caderno de programação, certificados, anais, etc.) será capturado a partir do cadastro realizado pelos autores no sistema e pelos arquivos anexados. Assim, o correto registro das informações e dos arquivos para publicação é de responsabilidade dos autores (destaca-se que o número máximo de autores é de 6, mantendo consistência com o número de autores que podem ser cadastrados no sistema por ocasião da submissão). Não serão atendidas solicitações de alterações posteriores em documentos (como anais, certificados, caderno de programação) decorrentes do registro equivocado de informações.

Por ocasião da submissão o autor deverá submeter dois arquivos: um sem identificação do(s) autor(es) para o blind review e o outro devidamente identificado, preparado para publicação. Ambos os arquivos devem ser submetidos em pdf. O arquivo para publicação pode ser substituído após o processo de avaliação em data definida para o upload dos trabalhos corrigidos.

Quadro 1: Perfil dos jovens entrevistados, na ocasião.

\begin{tabular}{|c|c|c|c|c|}
\hline Jovem & Residente & Ano Escolar & Tempo de NEAM & Idade \\
\hline Daniel & Vidigal & 2o ano & 5 anos & 16 anos \\
\hline Denison & Bonsucesso & 10 ano & 2 anos & 16 anos \\
\hline João Vitor & Pavuna & 3ㅇ ano & 3 anos & 17 anos \\
\hline Milena & Rocinha & 20 ano & 3 anos & 18 anos \\
\hline Patrick & Gávea (Minhocão) & 20 ano & 5 anos & 18 anos \\
\hline Rafael & Cidade de Deus & 2ㅇ ano & 2 anos & 18 anos \\
\hline
\end{tabular}

Fonte: Elaborado pelos autores, com base na pesquisa realizada (MOREIRA et, al. 2016)

Na primeira fase, após a atividade denomidana Ninho-Domo ${ }^{1}$, iniciou-se várias técnicas para coleta de dados, a primeira deu-se pela observação e registro da participação dos jovens na experiência. Na sequência os jovens, por meio de cartas, deram suas opiniões a respeito da

\footnotetext{
${ }^{1}$ Por meio do trabalho do barro, sisal, e fibras naturais, a atividade "Ninho-Domo" consiste no processo de construção que inicia com o Domo que estruturará "a casa do João de Barro". O caminhar entre as novidades e as experiências se fazem presentes no desenvolvimento da Arte e do Design Social, parte principal da pesquisa que apoia a tese de doutorado da autora, defendida em novembro de 2017.
} 
atividade. A análise dessas cartas contribuiu para elaborar o roteiro das entrevistas na qual se indagou sobre os dados pessoais, a participação no NEAM-LILD e sua crítica, os planos para o futuro, as expectativas alcançadas e auto avaliação. As manifestações dos jovens registradas por meio dos diferentes instrumentais de coleta foram analisadas como evidencias de impacto em relação aos indicadores pertinentes, anteriormente mencionados e publicados por Moreira et. al (2016).

Em oportunidade posterior, passado um ano, esse jovens foram novamente acionados para dar novos depoimentos. Dessa vez oportou-se pelo questionário online, acreditando que desta forma, eles poderia ter outra maneira de se manifestarem. Acresta-se o fato de que muitos já não faziam mais parte do núcleo, o que prejudicaria um novo encontro. Para nossa surpresa um deles já havia ingressado no nível superior. Abaixo registros das respostas, devidamente tabuladas. Importante destacar, que nesta fase não revelamos a identidade dos respondentes. Nem todas as perguntas foram respondidas por todos. Deixamos bem livre a vontade para que respondesse as questões garantindo seu conforto. Nesta sessão será exibido de forma compacta as respostas do questionário online, para posterior comentários e análises da sessão posterior.

\section{2 - Qual a sua formação?}

\section{5 respostas}

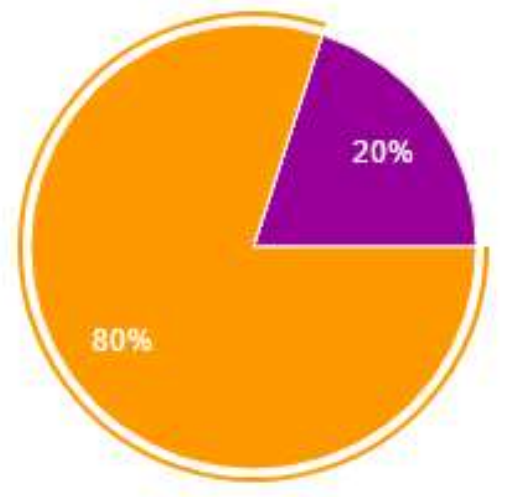

cursando o ensino fundamental

ensino fundamental completo

cursando o ensino médio

ensino médio completo

cursando nivel superior

superior completo

\section{De quais programas do NEAM você participou?}

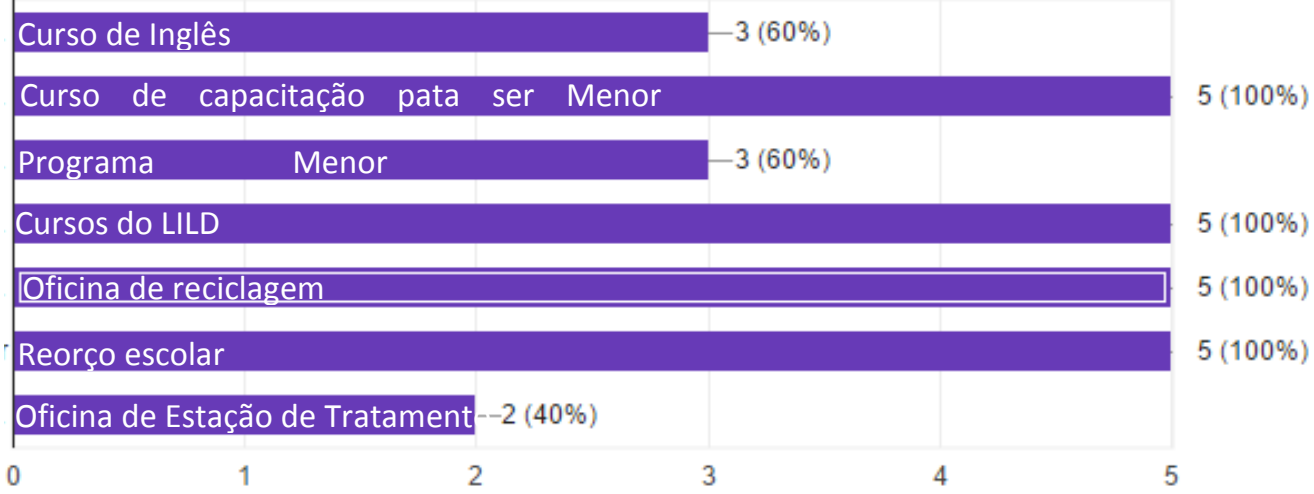


Qual você mais gostou? Justifique.

Jovem 1 - Menor Aprendiz. Me fez crescer mais e me ajudou a interagir melhor com as pessoas.

Jovem 2 - Oficina de Reciclagem.

Jovem 3 -Curso menor aprendiz. Porque além de ser o primeiro contato com um emprego, eu pude amadurecer, tanto profissionalmente como na minha vida pessoal, no meu caráter.

Jovem 4 - Ganhei bastante experiência com todos esses programas.

Jovem 5 - Oficina de reciclagem, pois aprendi a reaproveitar coisas que eram descartadas e dar uma nova vida a ela.

Jovem 6 - Gostei muito de trabalhar com o Professor Jose L. Ripper na pesquisa do Domo "Casa de João de Barro" Geodésico, conhecer todas aquelas formas de objeto que nunca tinha visto na vida, foi um grande desafio, e aprendi muito com as pessoas do LILD e no NEAM.

\section{Em que bairro você mora?}

Jovem 1 - Moro na Pavuna

Jovem 2 - Moro em Bonsucesso

Jovem 3 - Vivo na Rocinha.

Jovem 4 - Sou de Jacarepaguá

Jovem 5 - Mora na Gávea

Jovem 6 - Moro no Vidigal

Nos fale dos seus atuais planos para o futuro.

Jovem 1 - Fazer um curso técnico em administração

Jovem 2 - Engajar no quartel e seguir carreira no Exército

Jovem 3 - Pretendo me formar em design e trabalhar com fotografia.

Jovem 4 - Pretende fazer vestibular na PUC e me formar em Design Gráfico.

Jovem 5 - Terminar a faculdade de Design e depois cursar Belas Artes.

Jovem 6 - Desejo me formar na Cultura Inglesa e terminar o ensino médio. E trabalhar na área de informática.

\section{Como foi sua passagem pelo NEAM?}

Jovem 1 - Uma ótima passagem

Jovem 2 - Foi ótimo.

Jovem 3 - Foi de muito aprendizado e alegria. Aqui eu pude amadurecer muito e me tornar alguém de um caráter muito forte.

Jovem 4 - Fiz novas amizades, aprendi muitas coisas que posso levar para minha vida, e também ganhei muitas oportunidades.

Jovem 5 - Foi boa, aprendi coisas e conheci pessoas que estão comigo até hoje. 
Jovem 6 - Bem, eu ainda estou no NEAM, embora eu esteja a fazer um curso no LAC (Laboratório de Colaboração Avançada- PUC), posso dizer que tenho tido várias experiências boas e no LILD foi uma grande experiência e gostei muito.

\section{De tudo o que você pretendia viver aqui, o que aconteceu? E o que não aconteceu?}

Jovem 1 - Aconteceu tudo que eu esperava, comecei pelos cursos de férias e fui até o menor aprendiz.

Jovem 2 - Comecei a ter mais responsabilidade, me diverti aprendendo muitas coisas que irão me ajudar no meu futuro.

Jovem 3 - Criei muitas amizades que jamais pensei em criar. Aconteceu tudo o que eu pensei que iria viver aqui.

Jovem 4 - Fui para a Aparecida do Norte, que é um sonho meu desde criança. Infelizmente não consegui fazer um Pré Vestibular aqui.

Jovem 5 - Aconteceu tudo que eu esperava e mais um pouco.

Jovem 6 - Bem, é difícil descrever tudo, mais eu aposto que aprendi o suficiente para dar importância ao NEAM e ao LILD, mesmo sendo uma passagem breve nesse Laboratório onde eu aprendi a respeitar os colegas, a trabalhar em equipe e o que não aconteceu porque em algum momento vai acontecer.

\section{$O$ que você mais gostou no NEAM? O que podia melhorar?}

Jovem 1 - A equipe que trabalha no NEAM.

Jovem 2 - Das pessoas em geral. O espaço.

Jovem 3 - Da equipe do NEAM e do LILD. Eu acho que está bom do jeito que está.

Jovem 4 - Gosto bastante das formas que os professores ensinam se comunicam e etc. Já tem tudo o que é necessário.

Jovem 5 - A companhia e as coisas que aprendi com o NEAM.

Jovem 6 - No NEAM gostei de tudo, porque obtive várias oportunidades.

\section{5 - Você viveu alguma experiência no LILD?}
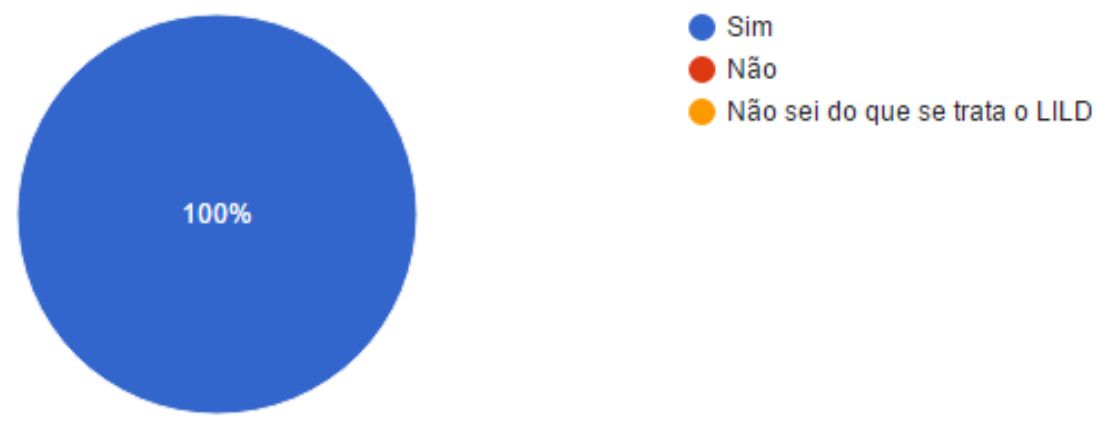


\section{Caso tenha respondido sim, comente esta experiência.}

Jovem 1 - Na feira de ciências da escola, foi uma das melhores experiências que eu já apresentei. Jovem 2 - Foi a melhor experiência que tive no NEAM, aprendi com o Prof. Ripper que podemos fazer tantas coisas com bamboo e barro, como por exemplo: Abrigos e Materiais de Sobrevivência. Jovem 3 - Foi um momento novo. Eu gostei muito, pois eu pude mexer com coisas que eu jamais pensei que iria mexer ou que se pudesse fazer coisas com certos objetos, como o bambu.

Jovem 4 - Fizemos muitos projetos com bambu, barro e outros. Construímos diversas estruturas, e muitas eram levadas ou feitas em Tinguá. Foi bastante gratificante, aprendi muitas coisas que se aplicaram no meu dia a dia e em trabalhos escolares por exemplo.

Jovem 6 - Foi uma experiência única, pois o trabalho era algo experimental que exigia muito esforço físico e mental, mais quando eu via aquele objeto pronto, era uma alegria muito grande, como em Tíngua e a maquete do LILD.93

\section{Viveu alguma outra experiência em outro setor da PUC? Qual? Comente.}

Jovem 1 - Sim. Laboratório de Colaboração Avançada (LAC-PUC-Rio). Uma oportunidade boa para crescer no mundo da informática

Jovem 2 - Departamento de História, onde trabalhei como auxiliar administrativo.

Jovem 3 - Não.

Jovem 4 - Eu fiz teatro na Cátedra e foi bastante divertido, pois eu perdi boa parte da minha timidez, e também fiz muitas amizades lá.

Jovem 5 - Participei de diversos workshops no CRAA e Visitei o Laboratório de Designer.

Jovem 6 - Bem agora me encontro a trabalhar no Laboratório de Colaboração Avançada (LAC-Rio), aprender a programar.

\section{Você acredita ter amadurecido no NEAM? Justifique.}

Jovem 1 - Sim. Depois que eu participei do NEAM, tive mais companheirismo, mais responsabilidade, pontualidade.

Jovem 2 - Sim. Mudei muito minha rotina, mudei meu conceito sobre "trabalhar".

Jovem 3 - Sim. Amadureci muito. O NEAM sem dúvidas tem uma grande porcentagem no meu crescimento. Aqui eu pude lidar com vários tipos de personalidades, e estilos.

Jovem 4 - Bastante. O NEAM nos ensina a como seguir a vida com humildade, ética e educação.

Jovem 6 - Sim, estar no NEAM durante esse tempo me possibilitou ver que eu podia ir além daquilo que eu esperava de mim.

\section{Principais resultados}

Toda a trajetória da parceria NEAM-LILD-Comunidade revela, através da observação continua, evidencias do impacto dessa vivencia nas mudanças comportamentais dos jovens do NEAM, especialmente, no que se refere aos indicadores antes mencionados e aqui enfatizados no que tange o respeito as individualidades, a abertura para novas experiências, o diálogo entre os participantes, a troca de ideias e opiniões, o delineamento participativo das metas prioritárias, a 
discussão de novas alternativas de trabalho e auto avaliação sobre o desempenho.

Por meio dos questionários online, emergiram informações e depoimentos significativos que consolidam o impacto esperado, como os resultados da primeira entrevista pesquisa. Apresentar os resultados quantitativamente em termos numéricos e percentuais extraídos das entrevistas não foi prioridade, face ao número de respondentes. Assim, optamos por uma análise prioritariamente qualitativa. O questionário online permitiu constatar: a participação prazerosa nos programas oferecidos, a vivência com sucesso nas atividades do NEAM-LILD, os acontecimentos significativos para a vida pessoal, expectativas alcançadas, aprendizagem e aplicação do conhecimento, busca de outras experiências na Universidade (PUC), o amadurecimento e gratidão.

O Design, pela sua natureza diversa, foi fundamental para corroborar com a abordagem desejada, somado a interdisciplinaridade, demandam características similares, tais como a curiosidade, abertura para o diferente e a inovação. Apesar da interdisciplinaridade não refutar completamente o especialíssimo ou a disciplinaridade em si, questionar essas premissas é algo importante. A vocação interdisciplinar do Design auxiliou a metodologia de investigação. Os resultados observados, tanto de experiências anteriores do NEAM e do LILD, quanto do conteúdo extraído das entrevistas, revela potencial transformador nos jovens vinculados a essas unidades da universidade, estabelecendo um "ganha-ganha" para todos os envolvidos. Descarta-se o papel assistencialista da universidade e é trazido á tona a oprtunidade de que estas instituições doem e recebam saberes, por meio de trocas.

A atitude interdisciplinar nos ajudou ainda a viver e a aprofundar a importância de abraçar o novo, de encarar a complexidade como vetor de oportunidades. A análise das entrevistas foi tão importante quanto a própria experiência de se realizar as entrevistas. Ou seja, transformar em dados ou números, algo que envolve a sensibilidade e a vivência, deixou de ser uma das intenções ao longo do processo. Notamos que a experiência da ação não é mensurável, pois cada indivíduo teve a sua troca, seu aprendizado durante a investigação. Apenas, desejamos que mais pesquisadores e jovens tenham a oportunidade que tivemos.

Este aprendizado por parte dos professores da Universidade, acostumados a trabalhar como referencial Universidade-Academia, se deu pelos incomodos em suas expectativas iniciais de interpretar e perceber a si próprios e ao outro grupo (jovens de comunidade de baixa renda). Nesse sentido, já alertava a Professora Maria helena Novas, do Departanento de Psicologia da PUC-Rio, que só ajuda alguém a crescer aquele que se propõe a crescer junto; só ensina alguma coisa aquele que está aberto para aprender e descobrir; só educa verdadeiramente quem vê diante de si uma trajetória de realização criativa, buscando sempre se renovar, demostrando profundo respeito pelo outro e pela própria vida (NOVAES, 1999).

Além disso, a convivência aberta nos proporcionou uma permanente autoavaliação. O processo da contratransferência vivenciando no dia a dia com os jovens adolescentes nos permitiu rever nossos postulados, exigindo da equipe uma autoanálise constante. Este processo, em que Devereux busca a revelação do objeto, determinou ao Projeto a busca da revelação dos jovens pelo conhecimento, uma vez que assim procedendo, estaríamos buscando a nós mesmos. É a troca manifestada pelo sabor de quem aprende. Tudo se relacionou de forma harmônica e prazerosa. A implicação afetiva e as atitudes resultantes do convívio foram sendo produzidas na relação, na influência de um para o outro. 0 inconsciente do pesquisador se relacionou com o inconsciente do aluno (jovem da Rocinha), nas diferentes formas que cada ciência se apresentou e através dos instrumentos que dispõe, ou seja, testes, questionários, atividades, estatísticas e outros. 


\section{Referências}

BERGSON, H. “Matéria e memória”, 1896.

CARVALHO, C. A escuta de memórias nos labirintos da favela: reflexões metodológicas sobre uma pesquisa-intervenção. Tese de Doutorado. PUC-Rio, 2015.

COUTO, R. M. S. Movimento interdisciplinar de designers brasileiros em busca de educação avançada. 1997. Tese. (Doutorado em Educação) - PUC-Rio, Rio de Janeiro, 1997. [= Blucher Design Proceedings, v. 9, n. 2]. DAL BIANCO, B.; DAMAZIO, V. Design em Parceria: Reflexões Sobre Um Modo Singular de Projetar Sob a Ótica do Design e Emoção. PUC-Rio. Dissertação (mestrado em Artes e Design). Pontifícia Universidade Católica do Rio de Janeiro, 2007.

FENTRESS, J. e C. WICKHAM. Memória Social. Lisboa: Teorema, 1992.

HALBWACKS, M. A memória coletiva. Trad. Beatriz Sidou. São Paulo: Centauro, 2006.

Moreira, Marina L.; Nogueira, Daniel Moura; Pina, Fernanda; Morenna, Janara; "INCLUSÃO DO JOVEM DE BAIXA RENDA NA UNIVERSIDADE ATRAVÉS DO DESIGN", p. 3352-3362 . In: Anais do 12응 Congresso Brasileiro de Pesquisa e Desenvolvimento em Design São Paulo: Blucher, 2016.

NOVAES, M.H. Compromisso ou alienação frente ao próximo século, Editora NAU, 1999.

POLLAK, M. Memória, esquecimento, silêncio, 1992.

THIOLLENT, M. Metodologia da Pesquisa-Ação. São Paulo: Cortez, 1985.

VELHO, Gilberto. Individualismo e Cultura: Notas Para Uma Antropologia Da Sociedade Contemporânea. Rio de Janeiro, Zahar, 2003. 